\title{
Oncological outcomes of function-preserving gastrectomy for early gastric cancer: a multicenter propensity score matched cohort analysis comparing pylorus-preserving gastrectomy versus conventional distal gastrectomy
}

\author{
Masaki Aizawa' ${ }^{1}$ Michitaka Honda ${ }^{2}$ - Naoki Hiki ${ }^{2}$ Takahiro Kinoshita ${ }^{3}$. \\ Hiroshi Yabusaki ${ }^{1} \cdot$ Souya Nunobe $^{2} \cdot$ Hidehito Shibasaki $^{3} \cdot$ Atsushi Matsuki $^{1}$ • \\ Masahiro Watanabe ${ }^{3}$ Takayuki Abe Ta $^{4}$
}

Received: 18 May 2016/Accepted: 12 September 2016/Published online: 26 September 2016

(c) The International Gastric Cancer Association and The Japanese Gastric Cancer Association 2016

\begin{abstract}
Objective This study aimed to clarify the oncological safety of pylorus-preserving gastrectomy (PPG) compared with conventional distal gastrectomy (DG).

Methods From three institutions specializing in cancer, the medical records for a cohort of 2898 consecutive patients who had undergone DG $(n=2208)$ or PPG $(n=690)$ for clinical stage I gastric cancer between January 2006 and December 2012 were analyzed. A propensity score for each patient was estimated on the basis of 38 preoperative clinical and tumor-related factors. After propensity score matching had been done, 1004 patients (502 DG patients, 502 PPG patients) were included in the analysis. The overall survival, relapse-free survival, and occurrence of secondary gastric cancer were then compared. The median observation period was 48.6 months (range 1-109.8 months).

Results The 5-year overall survival rate was $98.4 \%$ for the PPG group and $96.6 \%$ for the DG group (hazard ratio $0.48,95 \%$ confidence interval $0.21-1.09, P=0.07)$. The 3-year relapse-free survival rate was $99.5 \%$ for the PPG group and $98.0 \%$ for the DG group (hazard ratio 0.39,
\end{abstract}

Masaki Aizawa

maizawa@niigata-cc.jp

1 Department of Digestive Surgery, Niigata Cancer Center Hospital, 2-15-3, Kawagishicho, Niigata, Niigata 951-8566, Japan

2 Department of Gastroenterological Surgery, Gastroenterological Center, Cancer Institute Hospital of the Japanese Foundation for Cancer Research, Tokyo, Japan

3 Department of Surgical Oncology, National Cancer Center Hospital East, Kashiwa, Chiba, Japan

4 Department of Preventive Medicine and Public Health, Biostatistics Unit at the Center for Translational and Clinical Research, Keio University School of Medicine, Tokyo, Japan
$95 \%$ confidence interval $0.12-1.33, P=0.12$ ). Postoperative secondary gastric cancer was encountered in eight patients $(1.6 \%)$ in the PPG group and four patients $(0.8 \%)$ in the DG group. No significant differences in either overall survival, relapse-free survival, or the occurrence of secondary gastric cancer were observed between the two groups.

Conclusions Given the adequate estimation of the clinical tumor stage, the oncological safety of PPG for clinical T1N0 gastric cancer in the middle portion of the stomach was comparable to that of DG.

Keywords Gastric cancer · Pylorus-preserving gastrectomy $\cdot$ Propensity-matched score

\section{Introduction}

The gastric cancer mortality rate has decreased in recent decades in Japan, a trend that can be attributed to an increase in the diagnosis of early gastric cancer. According to the 2009 annual nationwide registry report of the Japanese Gastric Cancer Association, stage I gastric cancer had been diagnosed in $59.7 \%$ of the 12,577 registered patients. The report showed that the 5-year survival rate in patients with stage I gastric cancer was $90.3 \%$ [1]. Whereas a gastrectomy with extended lymph node dissection for gastric cancer now provides a sufficiently satisfactory prognosis [2, 3], the maintenance of quality of life has become as important as a radical cure. This circumstance has led us to pursue function-preserving procedures to overcome gastrectomy-related nutritional disorders.

A pylorus-reserving gastrectomy (PPG) was introduced in 1967 as a function-preserving surgery for gastric ulcer [4]. The procedure essentially features the preservation of 
the sphincteric function of the pylorus by retaining the prepyloric antrum. Theoretically, a PPG can maintain physiological gastric emptying, thereby preventing alkaline reflex. This modification was suggested to reduce the incidence of postoperative prandial symptoms and reduce body weight loss after a conventional distal gastrectomy (DG) [5].

PPG has recently attracted attention as a surgical procedure for early gastric cancer in Japan. Several single-institution retrospective case studies with large numbers of patients have consistently indicated the oncological safety of PPG [6-8]. However, the PPG procedure that was examined included the preservation of the nerve supply and blood flow to the pyloric antrum for the maintenance of pyloric function, resulting in the incomplete dissection of the suprapyloric and infrapyloric lymph nodes. The limited dissection of some regional lymph nodes could increase the likelihood of recurrence. Although previous reports have suggested that the possibility of metastasis to the suprapyloric and infrapyloric lymph nodes from early gastric cancer located in the middle portion of the stomach was negligible $[9,10]$, a comparison with conventional DG plus extended lymphadenectomy in a sufficient number of patients is required to establish the oncological adequacy of PPG.

We have conducted a large-scale retrospective review of a database of patients from three high-volume centers. The purpose of this study was to validate the safety of PPG compared with DG over a long observation period.

\section{Patients and methods}

\section{Study population and patient selection}

After ethics board approval had been obtained, a prospectively maintained database for the Niigata Cancer Center Hospital, the Cancer Institute Hospital of the Japanese Foundation for Cancer Research, and the National Cancer Center Hospital East was reviewed. A total of 2898 patients who met the following criteria were enrolled in the study: histologically proven gastric adenocarcinoma, clinical stage I (T1N0, T2N0, T1N1), and treatment with DG or PPG between January 2006 and December 2012. The exclusion criteria were the presence of synchronous or metachronous malignant disease and no sufficiently applicable clinical data. The staging was conducted according to the Union for International Cancer Control TNM classification (seventh edition).

To estimate the propensity score, 38 preoperative factors, including the patients' demographic information and tumor-related factors, were identified (Table 1). Tumorrelated factors were evaluated according to the Japanese classification of gastric cancer (third edition) [11]. Our study team composed of expert surgeons, epidemiologists, and biostatisticians optimized these factors to decide whether DG or PPG would be appropriate. The propensity score estimation and matching were performed by a biostatistician who was blinded to the perioperative and postoperative information. The score was computed with a logistic model, and greedy matching (ratio 1:1 without replacement) with a caliper of width 0.2 standard deviations of the logit of the estimated propensity score was performed. In addition to the propensity score matching, four factors (clinical $\mathrm{T}$ and $\mathrm{N}$ category, tumor location, and number of lesions as a preoperative diagnosis) were exactly matched to achieve a better balance. Finally, 1004 patients (502 in the DG group and 502 in the PPG group) were matched and included in the analysis. The balance of each covariate before and after the matching between the two groups was evaluated by the standardized differences [12]. An absolute value of the standardized differences of less than $10 \%$ was considered to be a relatively small imbalance (Table 2). The study flow diagram is shown in Fig. 1.

\section{Comparative analysis and statistics}

After matching had been performed, the clinical courses of the matched patients were identified from the medical records. The primary outcome was overall survival (OS). Secondary outcome measures included the duration of relapse-free survival (RFS), the recurrence site, postoperative morbidity, and the incidence of secondary gastric cancer from the remnant stomach. OS was calculated by the KaplanMeier method from the date of the surgery until the date of death or the date of last follow-up. RFS was calculated from the date of the gastrectomy to the date on which the first recurrence was diagnosed. Postoperative morbidity was defined as a severity of grade 3 or more according to the Clavien-Dindo classification [13, 14]. The stratified log-rank test was used to compare OS and RFS between the DG and PPG groups. The hazard ratios and $95 \%$ confidence intervals were estimated by the Cox proportional hazards model. When evaluating the other secondary outcomes, we compared continuous variables using the Mann-Whitney $U$ test and categorical variables using the chi-square test and Fisher's exact test. All the statistical tests were two-sided, and the statistical significance was defined as $P<0.05$. The statistical analyses were performed with the statistical analysis software package SPSS 9.0 (SPSS, Chicago, IL, USA).

\section{Results}

The patient characteristics and tumor-related factors for all patients and the matched patients are shown in Table 2 . Significant differences in the following preoperative 
Table 1 Preoperative factors used to estimate the propensity scores

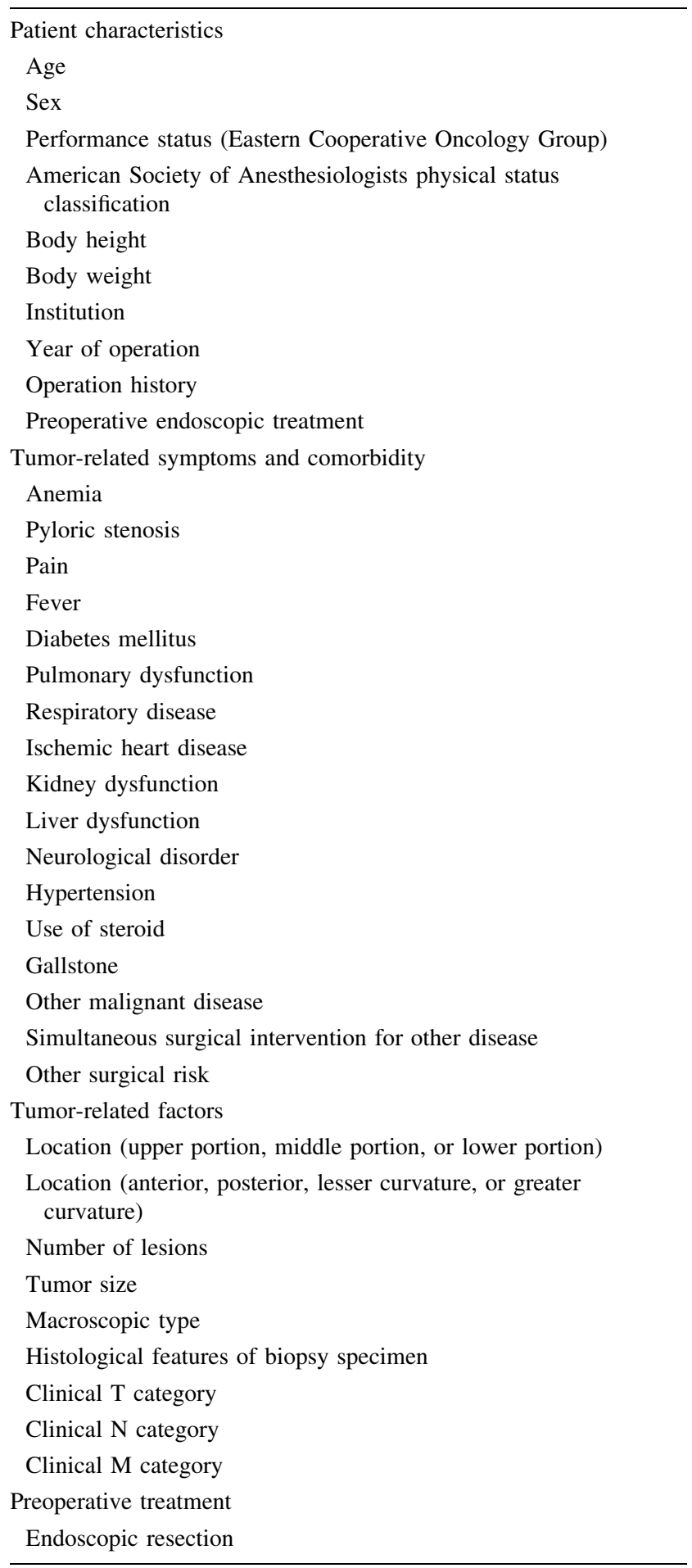

factors were observed between the DG and PPG groups: age, sex, American Society of Anesthesiologists physical status, body mass index, tumor location, clinical $\mathrm{T}$ category, clinical $\mathrm{N}$ category, and number of lesions. A young age, low American Society of Anesthesiologists physical status, middle-portion gastric tumor, solitary tumor, cT1 tumor, and $\mathrm{cNO}$ tumor were characteristic of the patients who underwent a PPG. After propensity score matching had been done, the distributions of the preoperative factors were comparable.

\section{Survival analysis}

The median observation period was 48.6 months (range $1-109.8$ months). The survival curve for OS is shown in Fig. 2. The 3- and 5-year OS rates were 97.9 and $96.6 \%$ respectively in the DG group and 98.7 and $98.4 \%$ respectively in the PPG group. The hazard ratio for overall death in the PPG group was 0.475 (95\% confidence interval $0.207-1.089 ; P=0.07$ ). The survival status is shown in Table 3. Death from gastric cancer occurred in 6 of the 16 patients who died after surgery. The RFS curve is shown in Fig. 3. The 3- and 5-year RFS rates were 98.0 and $98.0 \%$ respectively in the DG group and 99.5 and $99.5 \%$ respectively in the PPG group. The hazard ratio for recurrence in the PPG group was 0.393 (95\% confidence interval $0.116-1.331 ; P=0.12$ ). In 12 patients, recurrence after surgery was observed. The recurrence sites are shown in Table 3. In total, the peritoneum and liver were relatively frequent sites of recurrence.

\section{Surgical and pathological findings}

Table 4 shows the detailed surgical and pathological characteristics. Blood loss during surgery, the frequency of preservation of the vagal nerve, pathological $\mathrm{T}$ category, pathological stage, and tumor size in the resected specimen were significantly different between the two groups. In some of the patients, the histopathological stage was more advanced than the clinically estimated stage before surgery, the frequency of which was higher in the DG group. Microscopic residual tumor was present in four patients. All of these patients had pathological stage I cancer and a pathologically positive surgical margin. Although they survived during the observation period, peritoneal recurrence was found in one patient in the PPG group. In nine patients (not including three patients with microscopic residual tumor) with recurrence after DG, four were estimated as having pathological stage I cancer and another four had pathological stage II or stage III cancer. All four patients (including the one patient with microscopic residual tumor) with recurrence after PPG were had pathological stage I cancer.

The clinical course after surgery is shown in Table 3. The grade III or grade IV (overall) surgical morbidity rate was $3.4 \%(12.7 \%)$ in the DG group and $3.4 \%$ $(14.7 \%)$ in the PPG group. The postoperative 
Table 2 Patient characteristics and tumor-related factors at the baseline

\begin{tabular}{|c|c|c|c|c|c|c|}
\hline \multirow[t]{2}{*}{ Factors } & \multicolumn{3}{|c|}{ All patients $(n=2898)$} & \multicolumn{3}{|c|}{ Matched patients $(n=1004)$} \\
\hline & DG patients & PPG patients & Standardized difference & DG patients & PPG patients & Standardized difference \\
\hline Cases & 2208 & 690 & & 502 & 502 & \\
\hline Age $\left(\right.$ years) ${ }^{\mathrm{a}}$ & $63.8(11.3)$ & $58.7(10.4)$ & 45.6 & $61.7(11.4)$ & $60.7(9.6)$ & 10.0 \\
\hline \multicolumn{7}{|l|}{ Sex } \\
\hline Male & $1436(65.0 \%)$ & $385(55.8 \%)$ & 19.0 & $309(61.6 \%)$ & $301(60.0 \%)$ & 3.3 \\
\hline Female & $772(35.0 \%)$ & $305(44.2 \%)$ & -19.0 & $193(38.4 \%)$ & $201(40.0 \%)$ & -3.3 \\
\hline \multicolumn{7}{|l|}{ Year } \\
\hline 2006 & $316(14.3 \%)$ & $102(14.8 \%)$ & -1.3 & $81(16.1 \%)$ & $70(13.9 \%)$ & 6.1 \\
\hline 2007 & $292(13.2 \%)$ & $101(14.6 \%)$ & -4.1 & $73(14.5 \%)$ & $71(14.1 \%)$ & 1.1 \\
\hline 2008 & $288(13.0 \%)$ & $100(14.5 \%)$ & -4.2 & $57(11.4 \%)$ & $64(12.7 \%)$ & -4.3 \\
\hline 2009 & $348(15.8 \%)$ & $107(15.5 \%)$ & 0.7 & $74(14.7 \%)$ & $80(15.9 \%)$ & -3.3 \\
\hline 2010 & $334(15.1 \%)$ & $94(13.6 \%)$ & 4.3 & $65(12.9 \%)$ & $73(14.5 \%)$ & -4.6 \\
\hline 2011 & $341(15.4 \%)$ & $86(12.5 \%)$ & 8.6 & $74(14.7 \%)$ & $72(14.3 \%)$ & 1.1 \\
\hline 2012 & $289(13.1 \%)$ & $100(14.5 \%)$ & -4.1 & $78(15.5 \%)$ & $72(14.3 \%)$ & 3.4 \\
\hline \multicolumn{7}{|l|}{ ASA-PS } \\
\hline 1 & $929(42.1 \%)$ & $375(54.3 \%)$ & -24.8 & $236(47.0 \%)$ & $246(49.0 \%)$ & -4.0 \\
\hline 2 & $1160(52.5 \%)$ & $297(43.0 \%)$ & 19.1 & $248(49.4 \%)$ & $241(48.0 \%)$ & 2.8 \\
\hline 3 & $119(5.4 \%)$ & $18(2.6 \%)$ & 14.2 & $18(3.6 \%)$ & $15(3.0 \%)$ & 3.4 \\
\hline $\operatorname{BMI}\left(\mathrm{kg} / \mathrm{m}^{2}\right)^{\mathrm{a}}$ & $22.66(3.17)$ & $22.38(3.13)$ & 9.0 & $22.69(3.08)$ & $22.71(3.14)$ & -0.6 \\
\hline \multicolumn{7}{|l|}{ Tumor location } \\
\hline Upper portion & $110(5.0 \%)$ & $25(3.6 \%)$ & 6.7 & $16(3.2 \%)$ & $16(16 \%)$ & 0.0 \\
\hline Middle portion & $1106(50.1 \%)$ & $609(88.3 \%)$ & -90.8 & $435(86.7 \%)$ & $435(86.7 \%)$ & 0.0 \\
\hline Lower portion & $992(44.9 \%)$ & $56(8.1 \%)$ & 91.7 & $51(10.2 \%)$ & $51(10.2 \%)$ & 0.0 \\
\hline \multicolumn{7}{|l|}{ Clinical $\mathrm{T}$ category } \\
\hline T1a & $386(17.5 \%)$ & $291(42.2 \%)$ & -56.1 & $171(34.1 \%)$ & $171(34.1 \%)$ & 0.0 \\
\hline $\mathrm{T} 1 \mathrm{~b}$ & $1365(61.8 \%)$ & $391(56.7 \%)$ & 10.5 & $327(65.1 \%)$ & $327(65.1 \%)$ & 0.0 \\
\hline $\mathrm{T} 2$ & $457(20.7 \%)$ & $8(1.2 \%)$ & 65.9 & $4(0.8 \%)$ & $4(0.8 \%)$ & 0.0 \\
\hline \multicolumn{7}{|l|}{ Clinical N category } \\
\hline N0 & $2111(95.6 \%)$ & $682(98.8 \%)$ & -19.8 & $498(99.2 \%)$ & $498(99.2 \%)$ & 0.0 \\
\hline N1 & $97(4.4 \%)$ & $8(1.2 \%)$ & 19.8 & $4(0.8 \%)$ & $4(0.8 \%)$ & 0.0 \\
\hline \multicolumn{7}{|l|}{ Lesions } \\
\hline Solitary & $1994(90.3 \%)$ & $662(95.9 \%)$ & -22.4 & $481(95.8 \%)$ & $481(95.8 \%)$ & 0.0 \\
\hline Multiple & $214(9.7 \%)$ & $28(4.1 \%)$ & 22.4 & $21(4.2 \%)$ & $21(4.2 \%)$ & 0.0 \\
\hline Tumor size $(\mathrm{mm})^{\mathrm{a}}$ & $30.8(15.0)$ & $26.3(12.3)$ & 33.4 & $27.3(12.5)$ & $27.4(12.7)$ & 1.7 \\
\hline \multicolumn{7}{|l|}{ ESD/EMR } \\
\hline Absent & $1981(89.7 \%)$ & $617(89.4 \%)$ & 1.0 & $449(89.4 \%)$ & $447(89.0 \%)$ & 1.3 \\
\hline Present & $227(10.3 \%)$ & $73(10.6 \%)$ & -1.0 & $53(10.6 \%)$ & $55(11.0 \%)$ & -1.3 \\
\hline
\end{tabular}

ASA-PS American Society of Anesthesiologists physical status, BMI body mass index, DG distal gastrectomy, ESD/EMR preoperative endoscopic submucosal dissection and/or endoscopic mucosal resection, $P P G$ pylorus-preserving gastrectomy

a The average is given, with the standard deviation in parentheses

morbidities in the two groups were similar. The frequency of postoperative stasis was $1.8 \%$ in the DG group and $1.4 \%$ in the PPG group, with all the cases being either grade I or grade II. Although the morbidity rates were comparable between the two groups, the period of in-hospital stay in the PPG group was significantly longer than that in the DG group.

\section{Secondary gastric caner}

Secondary gastric cancer arose from the remnant stomach in four of the patients in the DG group and eight of the patients in the PPG group. However, data regarding endoscopic surveillance after surgery were not applicable in 582 patients. 


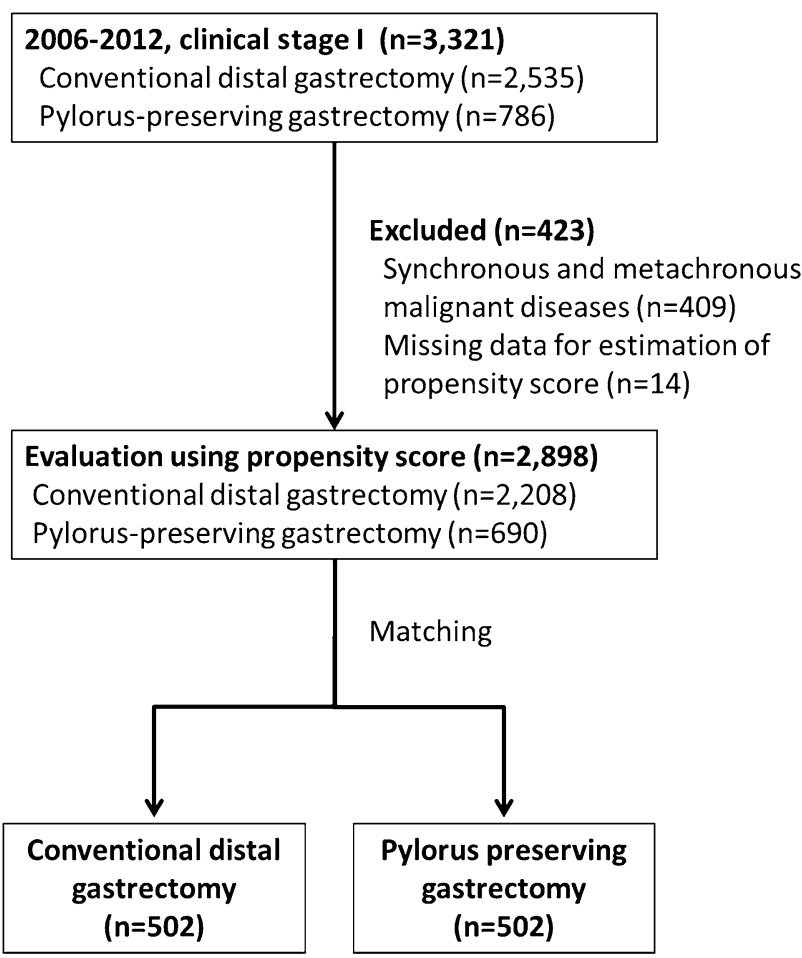

Fig. 1 Study flow diagram

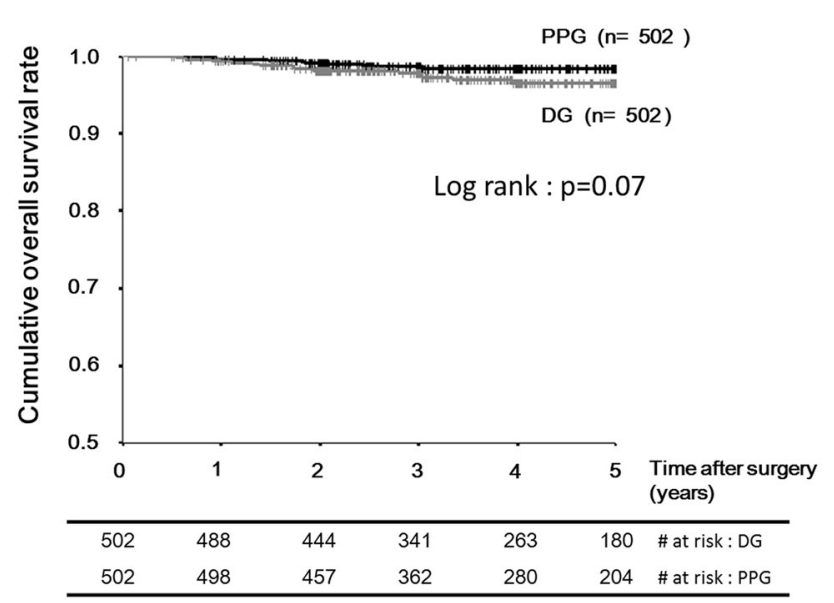

Fig. 2 Survival curve for overall survival after pylorus-preserving gastrectomy $(P P G)$ and conventional distal gastrectomy $(D G)$

\section{Discussion}

According to the Japanese gastric cancer treatment guidelines revised in 2010, PPG can be applied for clinical T1N0 gastric cancer in the middle portion of the stomach with a distal tumor border at least $4 \mathrm{~cm}$ proximal to the pylorus [15]. The potential risk of recurrence because of the omission of the dissection of a few lymph nodes during the PPG procedure remains controversial. So far, no randomized controlled trial evaluating the oncological safety of PPG for early gastric cancer has been performed. Previous
Table 3 Postoperative course

\begin{tabular}{|c|c|c|c|}
\hline Factors & DG patients & PPG patients & $P$ \\
\hline In-hospital stay (days) ${ }^{\mathrm{a}}$ & $10(7-41)$ & $11(7-78)$ & $<0.001$ \\
\hline Deaths & $0(0 \%)$ & $0(0 \%)$ & \\
\hline \multicolumn{4}{|l|}{ Morbidity ( $\geq$ grade III) } \\
\hline Absent & $485(96.6 \%)$ & $485(96.6 \%)$ & 0.569 \\
\hline Present & $17(3.4 \%)$ & $17(3.4 \%)$ & \\
\hline Anastomotic leakage & $3(0.6 \%)$ & $3(0.6 \%)$ & - \\
\hline Bleeding & $1(0.2 \%)$ & $0(0 \%)$ & \\
\hline Pancreas fistula & $4(0.8 \%)$ & $5(1.0 \%)$ & \\
\hline Abdominal abscess & $2(0.4 \%)$ & $1(0.2 \%)$ & \\
\hline Wound infection & $2(0.4 \%)$ & $2(0.4 \%)$ & \\
\hline Anastomotic stenosis & $1(0.2 \%)$ & $3(0.6 \%)$ & \\
\hline Gastrointestinal paralysis & $1(0.2 \%)$ & $0(0 \%)$ & \\
\hline Ascites & $1(0.2 \%)$ & $0(0 \%)$ & \\
\hline Pneumonia & $1(0.2 \%)$ & $1(0.2 \%)$ & \\
\hline Cardiac disorder & $0(0 \%)$ & $2(0.4 \%)$ & \\
\hline Other complication & $1(0.2 \%)$ & $0(0 \%)$ & \\
\hline \multicolumn{4}{|l|}{ Postoperative chemotherapy } \\
\hline No & $476(94.8 \%)$ & $488(97.2 \%)$ & 0.075 \\
\hline Yes & $26(5.2 \%)$ & $14(2.8 \%)$ & \\
\hline \multicolumn{4}{|l|}{ Recurrence } \\
\hline No & $484(96.4 \%)$ & $498(99.2 \%)$ & 0.192 \\
\hline Yes & $8(1.6 \%)$ & $4(0.8 \%)$ & \\
\hline Peritoneum & $3(0.6 \%)$ & $2(0.4 \%)$ & 0.521 \\
\hline Liver & $3(0.6 \%)$ & $1(0.2 \%)$ & \\
\hline Lung & $0(0 \%)$ & $0(0 \%)$ & \\
\hline Bone & $1(0.2 \%)$ & $0(0 \%)$ & \\
\hline Lymph node & $1(0.2 \%)$ & $0(0 \%)$ & \\
\hline Surgical site & $0(0 \%)$ & $1(0.2 \%)$ & \\
\hline \multicolumn{4}{|l|}{ Survival status } \\
\hline Alive & $486(96.8 \%)$ & $493(98.2 \%)$ & 0.488 \\
\hline Disease-specific death & $4(0.8 \%)$ & $2(0.4 \%)$ & \\
\hline Death from other disease & $7(1.4 \%)$ & $3(0.6 \%)$ & \\
\hline Not applicable & $5(1.0 \%)$ & $4(0.8 \%)$ & \\
\hline \multicolumn{4}{|l|}{ Secondary gastric cancer } \\
\hline Absent & $242(48.2 \%)$ & $166(33.1 \%)$ & 0.082 \\
\hline Present & $4(0.8 \%)$ & $8(1.6 \%)$ & \\
\hline Not applicable & $264(51.0 \%)$ & $318(65.3 \%)$ & \\
\hline
\end{tabular}

$D G$ distal gastrectomy, $P P G$ pylorus-preserving gastrectomy

a The median is given, with the range in parentheses

studies comparing DG and PPG were conducted with little regard to preoperative factors [10, 16-21]. In most of these studies, case matching was performed only according to the location of the tumor. In clinical practice, however, the surgical procedure is comprehensively determined on the basis not only of tumor-related factors but also of the patient's medical condition; hence, the results of these 


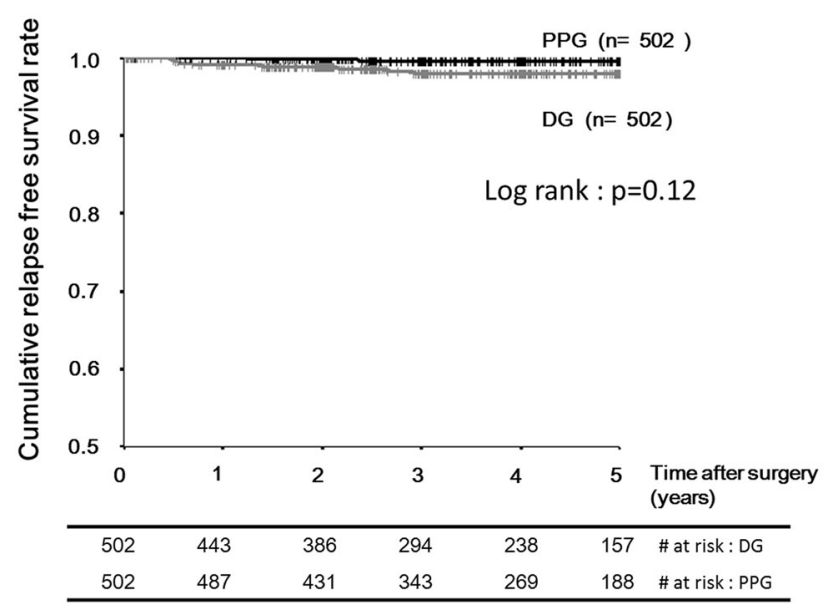

Fig. 3 Survival curve for relapse-free survival after pylorus-preserving gastrectomy $(P P G)$ and conventional distal gastrectomy $(D G)$

previous studies might have been influenced by other tendencies toward to each procedure. Although a case-matched comparison considering various clinical factors and one randomized controlled trial have been reported, their results had limited ability to establish the clinical benefit of PPG because of the relatively small numbers of cases and the relatively short observation periods [22, 23]. Here, we have reported the first large-scale case-controlled analysis of PPG using the propensity-matched score (PMS). The sample size and observation period of present the study were statistically designed to allow a sufficient comparison of the survival outcome between DG and PPG.

The propensity score method is increasingly being used in observational studies investigating surgical procedures for gastric cancer [24-26]. The PMS can be used to balance covariates in two nonrandomized groups so as to reduce biased estimations. At the baseline of the present study population, there was quite a large difference in the preclinical factors between the DG and PPG groups (Table 2). After the PMS dissolved the difference in conditional probability, the matched patients had no significant covariates between the two groups.

The results of a comparative evaluation suggested essential differences between the two procedures in terms of volume of blood loss, the level of lymph node dissection, and the preservation of the vagal nerve. On the other hand, the preoperative $\mathrm{T}$ category, stage, and tumor size were underestimated in some patients, and this was commoner in the DG group. To avoid undertreatment, surgeons may have estimated the clinical stage more carefully in the PPG group than in the DG group. This might have created an inevitable bias, even with use of the PMS method, in the present study.

Whereas the surgical morbidity rates were comparable between the two groups, the hospital stay in the PPG group was significantly longer than that in the DG group. This finding is consistent with previous reports $[16,20,22]$. Delayed gastric emptying is known to be more frequent in PPG patients [21]. The dissection of the infrapyloric vein and the right gastric vein was suggested to cause the longterm retention of the gastric contents following edema of the pyloric cuff $[20,27]$. The relatively low frequency of stasis in the present study presumably originated from the fact that the specialized gastric surgeons operating in highvolume centers were able to minimize the decrease in gastric motility through the proper preservation of the blood flow to the pyloric cuff. Nevertheless, a subtle retardation of food intake in patients who have undergone PPG has been reported in several studies $[16,22]$. This factor might be responsible for the extension of the hospital stay.

In the present study participants, lymph node dissection was consistently performed according to a standard procedure, although preservation of the infrapyloric vessels and/or abdominal branch of the vagal nerve was left to the surgeon's judgment. Although the lymph node dissection was performed according to the Japanese gastric cancer treatment guidelines [15], some limitations in lymph node dissection were encountered when a PPG was performed. The suprapyloric lymph nodes were not dissected to allow the preservation of the right gastric artery and vein. A portion of the infrapyloric lymph node was also not resected to preserve the infrapyloric artery.

Both OS and RFS were not significantly different between the PPG group and the DG group. The survival rate after PPG tended to be superior to that after DG. This was presumably attributable to the difference in the pathological stage. Previous studies have consistently reported 5-year OS rates of 95.0-98.0\% after PPG $[6-8,20]$. Among the extremely rare recurrences in both groups, no recurrences in lymph nodes were observed after PPG. Thus, for patients with a carefully estimated preoperative tumor stage, the survival rate after PPG for early gastric cancer can be considered excellent. In such cases, the curtailment of regional lymph node dissection is unlikely to cause any risk of recurrence. Among a total of 2898 patients, PPG was exceptionally performed for eight patients with cT2 tumor and eight patients with $\mathrm{cN} 1$ tumor. These small numbers of patients were not sufficient to assess the risk of PPG in the patients with T1N1 or T2N0 gastric cancer in the present study. However, since underestimation of the preoperative tumor stage could influence the frequency of recurrence after surgery, PPG for T1N1 or T2N0 gastric cancer could carry a considerable oncological risk. Therefore, PPG should be restricted to patients with T1N0 gastric cancer.

Secondary cancer in the remnant gastric stump could be another oncological risk. Many reports concerning gastric cancer from the remnant stomach have been published 
Table 4 Surgical factors and pathological findings in matched patients

\begin{tabular}{|c|c|c|c|}
\hline Factors & DG patients & PPG patients & $P$ \\
\hline Cases & 502 & 502 & - \\
\hline \multicolumn{4}{|l|}{ Surgical approach } \\
\hline Open & $200(39.8 \%)$ & $184(36.7 \%)$ & \multirow[t]{2}{*}{0.165} \\
\hline Laparoscopic & $302(60.2 \%)$ & $318(63.3 \%)$ & \\
\hline Operation time $(\min )^{a}$ & $198(84-462)$ & $206(80-497)$ & 0.051 \\
\hline Blood loss $(\mathrm{mL})^{\mathrm{a}}$ & $45(0-1750)$ & $37(0-830)$ & 0.03 \\
\hline \multicolumn{4}{|l|}{ Level of lymph node dissection } \\
\hline D1 & $264(52.6 \%)$ & $5020(100 \%)$ & \multirow[t]{2}{*}{$<0.001$} \\
\hline $\mathrm{D} 2$ & $238(47.4 \%)$ & & \\
\hline Retrieved lymph nodes ${ }^{\mathrm{a}}$ & $35(6-145)$ & $35(5-122)$ & 0.794 \\
\hline \multicolumn{4}{|c|}{ Preservation of abdominal branch of vagal nerve } \\
\hline No & $271(54.0 \%)$ & $47(9.4 \%)$ & \multirow[t]{2}{*}{$<0.001$} \\
\hline Yes & $231(46.0 \%)$ & $455(90.6 \%)$ & \\
\hline \multicolumn{4}{|l|}{ Reconstruction } \\
\hline Billroth I & $334(66.5 \%)$ & $0(0 \%)$ & \multirow[t]{4}{*}{-} \\
\hline Billroth II & $2(0.4 \%)$ & $0(0 \%)$ & \\
\hline Roux-en-Y & $166(33.1 \%)$ & $0(0 \%)$ & \\
\hline Gastrogastrostomy & $0(0 \%)$ & $502(100 \%)$ & \\
\hline \multicolumn{4}{|l|}{ Pathological T category } \\
\hline $\mathrm{T} 1 \mathrm{a}(\mathrm{M})$ & $228(45.4 \%)$ & $250(49.8 \%)$ & \multirow[t]{6}{*}{0.008} \\
\hline $\mathrm{T} 1 \mathrm{~b}(\mathrm{SM})$ & $206(41.0 \%)$ & $219(43.6 \%)$ & \\
\hline $\mathrm{T} 2(\mathrm{MP})$ & $42(8.4 \%)$ & $21(4.2 \%)$ & \\
\hline $\mathrm{T} 3(\mathrm{SS})$ & $18(3.6 \%)$ & $8(1.6 \%)$ & \\
\hline $\mathrm{T} 4 \mathrm{a}(\mathrm{SE})$ & $8(1.6 \%)$ & $3(0.6 \%)$ & \\
\hline $\mathrm{T} 4 \mathrm{~b}(\mathrm{SI})$ & $0(0 \%)$ & $1(0.2 \%)$ & \\
\hline \multicolumn{4}{|l|}{ Pathological N category } \\
\hline No & $444(88.4 \%)$ & $460(91.6 \%)$ & \multirow[t]{4}{*}{0.215} \\
\hline N1 & $43(8.6 \%)$ & $30(6.0 \%)$ & \\
\hline $\mathrm{N} 2$ & $8(1.6 \%)$ & $9(1.8 \%)$ & \\
\hline $\mathrm{N} 3$ & $7(1.4 \%)$ & $3(0.6 \%)$ & \\
\hline \multicolumn{4}{|l|}{ Pathological M category } \\
\hline M0 & $502(100 \%)$ & $502(100 \%)$ & \multirow[t]{2}{*}{1.0} \\
\hline M1 & $0(0 \%)$ & $0(0 \%)$ & \\
\hline \multicolumn{4}{|l|}{ Pathological stage } \\
\hline I & $458(91.2 \%)$ & $477(95.0 \%)$ & \multirow[t]{3}{*}{0.049} \\
\hline II & $36(7.2 \%)$ & $22(4.4 \%)$ & \\
\hline III & $8(1.6 \%)$ & $3(0.6 \%)$ & \\
\hline \multicolumn{4}{|l|}{ Histological appearance } \\
\hline Differentiated & $197(39.2 \%)$ & $178(35.5 \%)$ & \multirow[t]{4}{*}{0.446} \\
\hline Undifferentiated & $241(48.0 \%)$ & $258(51.4 \%)$ & \\
\hline Mixed & $62(12.4 \%)$ & $66(13.1 \%)$ & \\
\hline Others & $1(0.2 \%)$ & $0(0 \%)$ & \\
\hline Pathological tumor size $(\mathrm{mm})^{\mathrm{a}}$ & $28(2-130)$ & $25(2-95)$ & 0.004 \\
\hline \multicolumn{4}{|l|}{ Residual tumor } \\
\hline R0 & $499(99.4 \%)$ & $501(99.8 \%)$ & \multirow[t]{2}{*}{0.351} \\
\hline $\mathrm{R} 1$ & $3(0.6 \%)$ & $1(0.2 \%)$ & \\
\hline
\end{tabular}

$D G$ distal gastrectomy, $M$ mucosa, $M P$ muscularis propria, $P P G$ pylorus-preserving gastrectomy, $S E$ serosa, $S I$ structures adjacent to serosa, $S M$ submucosa, $S S$ subserosa

a The median is given, with the range in parentheses 
[28-31]. The regurgitation of bile or pancreatic juice has been thought to initiate carcinogenesis through mucosal damage in the remnant stomach [32-34]. The preservation of the pylorus ring during a DG would assuage gastritis by reducing the reflux of the duodenal contents. Contrary to expectations, the reported prevalence of secondary gastric cancer after PPG was not negligible, but was $0.8-4.3 \%$ $[6,8,18,21,35]$. The results of the present study suggest a higher frequency of secondary gastric cancer after PPG compared with after DG. The frequencies after each procedure in this study agreed with those of previous analyses. However, whether PPG for early gastric cancer increases the risk of secondary gastric cancer could not be concluded, since the results of endoscopic examinations were not applicable for more than half of the study participants. In addition, the observation period was not adequate to evaluate the frequency of secondary gastric cancer.

The present study had several limitations. First, the evidence of a case-matched retrospective analysis is not as well established as that of a randomized controlled trial. Case matching using PMS could not offset all biases. The case matching in the present study was performed with a matching ratio of 1:1 without regard to the considerably lower frequency of PPG compared with DG. Overall, three quarters of the patients who underwent DG were excluded from the present analysis. In some of them, the tumor status was even similar to that of the patients in the PPG group. The patient selection, which was not equivalent between the two groups, might have influenced the results. Second, the matched patients included in the present analysis were a subgroup of patients who exhibited some distinct clinical features. The results of the present study might not necessarily be applicable to all early gastric cancer patients. For example, early gastric cancer is not common in most of the world. Thus, PPG might be applicable only in countries with a high incidence of gastric cancer. Third, the PPG procedure itself has not been completely established. The degree of blood flow and nerve preservation may depend on institutional policies or the abilities of surgeons. However, the fact that the quality of the lymph node dissections was well controlled in the present study should be considered when one is interpreting the results. Fourth, a longer observation period would have clarified the results of survival analysis in the present study. Nevertheless, the superior OS and RFS rates observed for the PPG group suggest that PPG offered a survival benefit at least comparable to that offered by DG after surgery. This result was acceptable for comparison of the oncological outcomes between the two groups. Fifth, the ability of PPG to alleviate disorders after a gastrectomy remains to be validated. Previous reports evaluating small numbers of patients have suggested that PPG for early gastric cancer reduced the incidence of postprandial symptoms, reduced body weight loss, reduced serum nutritional indices, improved endoscopic findings of the remnant stomach, and reduced the incidence of gallstones [17-19, 21-23]. A comparative analysis of a larger number of patients is needed to reveal whether the clinical benefit of PPG warrants a longer hospital stay.

In conclusion, this study was the first comparative casematched analysis between PPG and DG with a sufficient number of patients. Among carefully selected gastric cancer patients, PPG had no oncological inferiority to DG. Therefore, PPG might provide physiological advantages over DG by preserving the function of the pylorus without increasing the risk of recurrence.

\section{Compliance with ethical standards}

Conflict of interest The authors declare that they have no conflict of interest.

Ethical standards All procedures followed were in accordance with the ethical standards of the responsible committee on human experimentation (institutional and national) and with the Helsinki Declaration of 1964 and later versions. Informed consent or substitute for it was obtained from all patients for their being included in the study.

\section{References}

1. Nashimoto A, Akazawa K, Isobe Y, Miyashiro I, Katai H, Kodera $\mathrm{Y}$, et al. Gastric cancer treated in 2002 in Japan: 2009 annual report of the JGCA nationwide registry. Gastric Cancer. 2013;16:1-27.

2. Songun I, Putter H, Kranenbarg EM, Sasako M, van de Velde CJ. Surgical treatment of gastric cancer: 15-year follow-up results of the randomised nationwide Dutch D1D2 trial. Lancet Oncol. 2010;11:439-49.

3. Wu CW, Hsiung CA, Lo SS, Hsieh MC, Chen JH, Li AF, et al. Nodal dissection for patients with gastric cancer: a randomised controlled trial. Lancet Oncol. 2006;7:309-15.

4. Maki T, Shiratori T, Hatafuku T, Sugawara K. Pylorus-preserving gastrectomy as an improved operation for gastric ulcer. Surgery. 1967;61:838-45.

5. Sekine T, Sato T, Maki T, Shiratori T. Pylorus-preserving gastrectomy for gastric ulcer-one- to nine-year follow-up study. Surgery. 1975;77:92-9.

6. Morita S, Katai H, Saka M, Fukagawa T, Sano T, Sasako M. Outcome of pylorus-preserving gastrectomy for early gastric cancer. Br J Surg. 2008;95:1131-5.

7. Hiki N, Sano T, Fukunaga T, Ohyama S, Tokunaga M, Yamaguchi T. Survival benefit of pylorus-preserving gastrectomy in early gastric cancer. J Am Coll Surg. 2009;209:297-301.

8. Matsuki A, Nashimoto A, Yabusaki H, Nakagawa S. Long-term clinical outcome and survival after pylorus-preserving gastrectomy. Hepatogastroenterology. 2012;59:2012-5.

9. Kong SH, Kim JW, Lee HJ, Kim WH, Lee KU, Yang HK. The safety of the dissection of lymph node stations 5 and 6 in pyloruspreserving gastrectomy. Ann Surg Oncol. 2009;16:3252-8.

10. Kim BH, Hong SW, Kim JW, Choi SH, Yoon SO. Oncologic safety of pylorus-preserving gastrectomy in the aspect of micrometastasis in lymph nodes at stations 5 and 6. Ann Surg Oncol. 2014;21:533-8.

11. Japanese Gastric Cancer Association. Japanese classification of gastric carcinoma. 3rd English edition. Gastric Cancer. 2011;14:101-112. 
12. Bangalore S, Guo Y, Samadashvili Z, Blecker S, Xu J, Hannan EL. Everolimus-eluting stents or bypass surgery for multivessel coronary disease. N Engl J Med. 2015;372:1213-22.

13. Clavien PA, Barkun J, de Oliveira ML, Vauthey JN, Dindo D, Schulick RD, et al. The Clavien-Dindo classification of surgical complications: five-year experience. Ann Surg. 2009;250:187-96.

14. Dindo D, Demartines N, Clavien PA. Classification of surgical complications: a new proposal with evaluation in a cohort of 6336 patients and results of a survey. Ann Surg. 2004;240:205-13.

15. Japanese Gastric Cancer Association. Japanese gastric cancer treatment guidelines 2010 (ver. 3). Gastric Cancer. 2011;14:113-123.

16. Sawai K, Takahashi $\mathrm{T}$, Fujioka $\mathrm{T}$, Minato $\mathrm{H}$, Taniguchi $\mathrm{H}$, Yamaguchi T. Pylorus-preserving gastrectomy with radical lymph node dissection based on anatomical variations of the infrapyloric artery. Am J Surg. 1995;170:285-8.

17. Imada T, Rino Y, Takahashi M, Suzuki M, Tanaka J, Shiozawa $\mathrm{M}$, et al. Postoperative functional evaluation of pylorus-preserving gastrectomy for early gastric cancer compared with conventional distal gastrectomy. Surgery. 1998;123:165-70.

18. Nagano H, Ohyama S, Sakamoto Y, Ohta K, Yamaguchi T, Muto $\mathrm{T}$, et al. The endoscopic evaluation of gastritis, gastric remnant residue, and the incidence of secondary cancer after pyloruspreserving and transverse gastrectomies. Gastric Cancer. 2004;7:54-9.

19. Nunobe S, Sasako M, Saka M, Fukagawa T, Katai H, Sano T. Symptom evaluation of long-term postoperative outcomes after pylorus-preserving gastrectomy for early gastric cancer. Gastric Cancer. 2007;10:167-72.

20. Ikeguchi M, Hatada T, Yamamoto M, Miyake T, Matsunaga T, Fukuda K, et al. Evaluation of a pylorus-preserving gastrectomy for patients preoperatively diagnosed with early gastric cancer located in the middle third of the stomach. Surg Today. 2010;40:228-33.

21. Suh Y-S, Han D-S, Kong S-H, Kwon S, Shin C-I, Kim W-H, et al. Laparoscopy-assisted pylorus-preserving gastrectomy is better than laparoscopy-assisted distal gastrectomy for middlethird early gastric cancer. Ann Surg. 2014;259:485-93.

22. Shibata C, Shiiba KI, Funayama Y, Ishii S, Fukushima K, Mizoi $\mathrm{T}$, et al. Outcomes after pylorus-preserving gastrectomy for early gastric cancer: a prospective multicenter trial. World J Surg. 2004;28:857-61.
23. Park DJ, Lee H-J, Jung HC, Kim WH, Lee KU, Yang H-K. Clinical outcome of pylorus-preserving gastrectomy in gastric cancer in comparison with conventional distal gastrectomy with Billroth I anastomosis. World Surg. 2008;32:1029-36.

24. Hasegawa S, Kunisaki C, Ono H, Oshima T, Fujii S, Taguri M, et al. Omentum-preserving gastrectomy for advanced gastric cancer: a propensity-matched retrospective cohort study. Gastric Cancer. 2013;16:383-8.

25. Yasunaga H, Horiguchi H, Kuwabara K, Matsuda S, Fushimi K, Hashimoto $\mathrm{H}$, et al. Outcomes after laparoscopic or open distal gastrectomy for early-stage gastric cancer: a propensity-matched analysis. Ann Surg. 2013;257:640-6.

26. Kim HH, Han SU, Kim MC, Hyung WJ, Kim W, Lee HJ, et al. Long-term results of laparoscopic gastrectomy for gastric cancer: a large-scale case-control and case-matched Korean multicenter study. J Clin Oncol. 2014;32:627-33.

27. Hiki N, Nunobe S, Kubota T, Jiang X. Function-preserving gastrectomy for early gastric cancer. Ann Surg Oncol. 2013;20:2683-92.

28. Kaneko K, Kondo H, Saito D, Shirao K, Yamaguchi H, Yokota T, et al. Early gastric stump cancer following distal gastrectomy. Gut. 1998;43:342-4.

29. Newman E, Brennan MF, Hochwald SN, Harrison LE, Karpeh MS Jr. Gastric remnant carcinoma: just another proximal gastric cancer or a unique entity? Am J Surg. 1997;173:292-7.

30. Stalsberg H, Taksdal S. Stomach cancer following gastric surgery for benign conditions. Lancet. 1971;2:1175-7.

31. Toftgaard C. Gastric cancer after peptic ulcer surgery. A historic prospective cohort investigation. Ann Surg. 1989;210:159-64.

32. Byrne JP, Attwood SE. Duodenogastric reflux and cancer. Hepatogastroenterology. 1999;46:74-85.

33. Miwa K, Hasegawa H, Fujimura T, Matsumoto H, Miyata R, Kosaka $\mathrm{T}$, et al. Duodenal reflux through the pylorus induces gastric adenocarcinoma in the rat. Carcinogenesis. 1992;13:2313-6.

34. Sugiyama Y, Sohma H, Ozawa M, Hada R, Mikami Y, Konn M, et al. Regurgitant bile acids and mucosal injury of the gastric remnant after partial gastrectomy. Am J Surg. 1987;153:399-403.

35. Miyashita T, Miwa K, Inokuchi M, Nakagawara H, Tajima H, Takamura $\mathrm{H}$, et al. Spontaneous clearance of Helicobacter pylori after pylorus-preserving gastrectomy for gastric cancer. Oncol Rep. 2013;30:299-303. 